\title{
The precipitous decline of academic medicine in the United States
}

\section{Richard Balon, MD}

Departments of Psychiatry and Behavioral Neurosciences and Anesthesiology Wayne State University Detroit, Michigan, USA

Mary K. Morreale, MD

Department of Psychiatry and

Behavioral Neurosciences

Wayne State University

Detroit, Michigan, USA

\section{CORRESPONDENCE}

Richard Balon, MD

Departments of Psychiatry

and Behavioral Neurosciences

and Anesthesiology

Wayne State University

Tolan Park Building, 3rd floor

3901 Chrysler Service Drive

Detroit, MI 48201 USA

E-MAIL

rbalon@wayne.edu
$\mathrm{T}$ he recent coronavirus pandemic has made us more aware of the gradual decline of academic medicine. Although much has been written about the systemic problems in medicine and academia (mostly in the context of burnout and well-being), the problems in academic medicine extend well beyond these concerns.

Structural problems in academic medicine exist within all parts of its tripartite mission: education, clinical care, and research. With clinical care, there are tedious requirements for documentation in difficult-to-navigate electronic medical record systems, demands on productivity in the form of ever-increasing allocated Relative Value Units (RVUs), and senseless demands from managed-care organizations. All of these clinical demands reduce the time for teaching, which, ironically, university deans expect us instructors to increase. Similarly, education has been increasingly regulated by what has been referred to as the "medical-education industrial complex." ${ }^{1}$ Regulatory agencies have introduced changes with possibly negative consequences and no evident benefit. ${ }^{2,3}$ The promise that the new accreditation system would make residency training programs easier to manage has not materialized and, actually, the opposite appears true. In addition, unfunded mandates of questionable value have been introduced, such as the Clinical Skills Verification examination. ${ }^{4}$

Academic research-at least in psychiatry-has been experiencing an "intellectual crisis,"5,6 leading to the conclusion that "evidence-based medicine does not appear to provide an adequate scientific background for challenges of clinical practice in psychiatry and needs to be integrated with clinical judgment." ${ }^{7}$ Some argue that the scope of evidence-based medicine is limited and should be combined with practice-based evidence in making clinical decisions. ${ }^{8}$ And despite the glow that research funding brings to investigators and administrators, the sad fact is that, for the institution, research is a money loser. ${ }^{9}$

The pandemic has lifted the veil on even more serious threats to academic medicine. In a recent article, ${ }^{10}$ Johns Hopkins University Professor 
of History François Furstenberg describes the shifting landscape at one of our nation's top medical schools. Due to the pandemic, in anticipation of a loss of $>\$ 350$ million, Johns Hopkins “imposed a hiring freeze, canceled all raises, and warned about impending furloughs and layoffs...." and "suspended contributions to its employees' retirement accounts." ${ }^{10}$ Why was this decision made when Johns Hopkins had $\$ 10$ billion in assets and a $\$ 6$ billion endowment? ${ }^{10}$ Furstenberg blames this failure on university leadership and the corporatization of academic medicine. The cuts, he writes, were made by a coterie of administrators advising the university's president-decisions all made without any meaningful input from faculty. He states that administrative power has been consolidated into the hands of executives who execute decisions on high "... with little appreciation for transparency or inclusiveness, and little understanding of the academy's mission," and "these managers increasingly make decisions behind closed doors and execute them from above." ${ }^{10}$ This lack of transparency and understanding is truly worrisome. Among many administrators at Johns Hopkins, only one had significant classroom and research experience and, collectively, the number of JDs and MBAs far exceeds the number of PhDs. (Furstenberg does not mention any individuals with MDs in the leadership, although, in all fairness, some universities do have them at their helm.)

Leadership compensation at Johns Hopkins is similar to the business world, with the university's president earning \$1.6 million in salary and an additional \$1.1 million in deferred and other types of compensation. ${ }^{10}$ (This does not include the $\$ 310,000$ he made sitting on the board of T. Rowe Price, whose CEO serves on the Johns Hopkins Board of Trustees.) Furstenberg asserts that with this corporate mindset, leaders "have lost sight of an essential truth: A university exists for values different from those that dominate the for-profit world. A university governed by long timelines and long-term thinking grows conservatively and cautiously and prepares itself prudently for potential crises. If you turn a university into a giant corporation, on the other hand, it will rise and fall with the business cycle."10

Furstenberg suggests that Johns Hopkins may be the "canary in the coal mine of elite research universities." ${ }^{10}$ Is it possible that these issues are already widespread? We certainly have heard of many academic physicians who were forced to take pay cuts and/or lost employee retirement contributions due to the pandemic. In addition,
Johns Hopkins is not the only institution where leaders' salaries rival those of CEOs in the corporate world. In Michigan, for example, the CEO of the William Beaumont Health system affiliated with Oakland University had a total compensation of $\$ 5.9$ million in 2018, with a base salary of $\$ 1.85$ million, a bonus of $\$ 1.6$ million, deferred compensation of $\$ 1.66$ million, and $\$ 810,000$ in other compensation. Similarly, the Dean of the University of Michigan Medical School (and Executive Office for Medical Affairs and CEO of Michigan Medicine) has a base salary of $\$ 1.4$ million.

Corporate medicine and corporate academic medicine clearly behave like other industries and are treating their most valuable capital-their human capital-as interchangeable work units. The bottom line and leading principle are always profit and finances, whether the hospital or academic medical center is not-for-profit or for profit. Yet, as Furstenberg writes, “... university executives have revealed themselves ineffective in one of the most basic corporate responsibilities: managing financial risk." ${ }^{10}$

What does the Johns Hopkins experience mean for academic medicine? Although a single uniform definition of an academician has never been established, excelling in just 1 of the 3 of its main missions-education, clinical care, and research-does not suffice and "a good definition of an academician would require involvement in at least several additional interdependent activities such as mentoring, clinical care, writing, speaking, and participating in communities of professionals organized to advance and share knowledge." ${ }^{11}$ It is doubtful that these activities would be supported in a corporate environment because there is no revenue stream to pay for them. In addition, physician well-being would likely suffer. As Richard Summers writes, the expansion of hospital systems, clinics, health plans, and insurance companies results in "deprofessionalization, commoditization, and a new role for physicians as service providers in a complex corporate marketplace." ${ }^{12}$ It is doubtful that patient care would improve, and thus far, transformations in the health care industry in the forms of mergers, takeovers, and various other types of business transactions have not been based on patient needs or population needs. Rather, decisions are made based almost entirely on for-profit business models.

We must ask ourselves if we are experiencing similar changes at our own medical schools and medical centers. If so, are we listening to Furstenberg's warning? 
Like revelations regarding health care disparities that exist within our country, perhaps the pandemic has revealed the true face of corporate medicine. Furstenberg describes Johns Hopkins as the canary in the coal mine of elite research universities. Are our conveniently blind and hidden corporate leaders leading us like the Pied Piper led the children of Hamelin? Will academic medicine disappear with only the lame, deaf, and blind staying behind like in the Pied Piper legend?
Furstenberg notes that university hospitals operate "as money-generating conglomerates, rather than for [the larger purpose of] research, teaching, and public health" where "Faculty research is valued for its potential to be monetized and commercialized." ${ }^{10}$ Can an academic mission possibly be accomplished in this type of environment, or might we be witnessing the collapse of academic medicine due to corporate takeover? Will corporatization and commoditization spell the end of academic medicine?
REFERENCES

1. Balon R, Beresin EV, Guerrero A. Medicaleducation-industrial complex? Acad Psychiatry. 2018; 42:495-497.

2. Willett LL. The impact of a pass/fail Step $1-a$ residency program director's view. $\mathrm{N}$ Engl J Med. 2020; 382:2387-2389.

3. Makhoul AT, Pontell ME, Kumar NG, et al. Objective measures needed - program directors' perspectives on a pass/fail USMLE Step 1. N Engl J Med. 2020;382:2389-2392.

4. Balon R, Beresin EV, Guerrero APS, et al. Clinical Skills Verification: a problematic examination. Acad Psychiatry. 2020;44:255-259.
5. Fava GA. The intellectual crisis of psychiatric research. Psychother Psychosom. 2006;75:202-208.

6. Fava GA. Road to nowhere. World Psychiatry. 2014;13:49-50.

7. Fava GA. Clinical judgment in psychiatry. Requiem or reveille? Nord J Psychiatry. 2013;67: $1-10$

8. Duggal R, Menkes DB. Evidence-based medicine in practice. Int J Clin Pract. 2011;65:639-644.

9. Clayman RV. The compleat dean: a guide to academic leadership in an age of uncertainty. Scotts Valley, CA: CreateSpace Independent Publishing Platform; 2016.
10. Furstenberg F. University leaders are failing: the pandemic reveals ineptitude at the top. Change is needed. The Chronicle of Higher Education. 2020;66:30-31. https://www.chronicle.com/ article/university-leaders-are-failing. Accessed September 2, 2020 .

11. Balon R, Coverdale J, Roberts LW. Academician: what's in a name? Acad Psychiatry. 2010;34:169-171. 12. Summers RF. The social context of physician burnout. In: LoboPrabhu S, Summers RF, Moffic HS, eds. Combating physician burnout. A guide for psychiatrist. Washington, DC: American Psychiatric Association Publishing; 2020:27-42. 